\title{
Transient neonatal myasthenia gravis
}

INSERM

\section{Source}

INSERM. (1999). Orphanet: an online rare disease and orphan drug data base. Transient neonatal myasthenia gravis. ORPHA:391504

Transient neonatal myasthenia gravis (MG) is a rare form of MG (see this term) occurring in neonates born to mothers who have the disorder or specific circulating autoantibodies. 